\title{
From the Ancient Diets to the Recent Acquisitions on the Role of Brain Inflammation in Epilepsy, Are there Any Links?
}

Paolo Mainardi ${ }^{{ }^{*}}$, Paolo Carta ${ }^{2}$, Pasquale Striano ${ }^{3}$, Michele Mainardi ${ }^{4}$ and Massimo Montinari ${ }^{5}$

${ }^{1}$ Department of Neurosciences, University of Genova, Italy

${ }^{2}$ Department of Public Health, Genova, Italy

${ }^{3}$ Department of Neurosciences, Maternal and Child Health University of Genoa, Genova, Italy

${ }^{4}$ Majoring in medicine, degree thesis on neurology, University of Genova, Italy

${ }^{5}$ Visiting Professor Miami Cardiac \& Vascular Institute Baptist Hospital, USA

*Corresponding author: Paolo Mainardi, Department of Neurosciences, Rehabilitation, Ophthalmology, Genetics, Maternal and Child Health, University of Genova, Italy, Tel: +990103537068; Fax: +990103537080; E-mail: pmainardi@neurologia.unige.it

Received date: June 30, 2015; Accepted date: July 28, 2015; Published date: August 03, 2015

Copyright: $\bigcirc 2015$ Mainardi P et al. This is an open-access article distributed under the terms of the Creative Commons Attribution License, which permits unrestricted use, distribution, and reproduction in any medium, provided the original author and source are credited.

\begin{abstract}
Recent studies put in evidence the role of brain inflammation in the pathogenetic mechanisms of seizures. It has been reported that an intestinal inflammation may be able to migrate to the brain, thus an intestinal inflammation could be the original cause of epilepsy, as osteopaths believed in the ' $20 \mathrm{~s}$. We attempted to demonstrate the role of gut-brain axis in epilepsy on the basis of recent acquisitions.
\end{abstract}

Keywords: Ketogenic diet; Inflammation; Intestine; Gut-brain axis

\section{Manuscript}

Surely, the diet is the oldest form of medicine, used to treat diseases since ancient times. According to Hippocrates (460 BC) "every patient requires a diet." Early as $300 \mathrm{BC}$, Erasistratus put in evidence a connection between epilepsy, intestine and digestive organs. In the second century, Galen refered to diet and purges to control crisis. In the eighteenth century, Arnold of Villanova considered the diet as the most important aspect in the treatment of epilepsy. In the twenties, fasting was widely used to control seizures [1], and its efficacy was linked to ketosis. Later, in 1866, a diet rich in fats and poor in carbohydrates was proved to produce ketosis, hence it was suggested to control seizures, and named ketogenic diet (KD).

A recently published meta-analysis [2] on a total of 38 studies shows that the success rate of the patients following the KD was $58,4 \%$ at 3 months and $42,8 \%$ at 6 months. However, it must be kept into consideration that about $50 \%$ of patients dropped out at 6 months, mainly for its scarce palatability.

Major limitation to evaluate the diet's efficacy by gold standard protocols is that it cannot be administered to patients following the double-blind, crossover vs. placebo studies. For this reason the diet is nowadays largely considered as non-conventional medicine.

However, in 2008 Helen Cross conducted a pseudo-controlled study on the $\mathrm{KD}$, through random enrollment of about 100 children: half of them received drug treatment, using drugs available in 2008, the second half were put on KD. At six months of treatment, the result of this study showed a $30 \%$ average worsening in the number of seizures in pharmacologically treated patients, while the group treated with KD had achieved a seizure average reduction of about 30\% [3].

Today, we know that ketones are not responsible for anticonvulsant action [4]. In fact, the hypoglycemic diet, which does not produce ketosis, already proposed by Lennox in 1928 [5], produces results similar to those of KD [6].

Unveiling KD's mechanism of action could be helpful to understand the pathogenesis of epilepsy. In particular, its large spectrum of action on different types of seizures [7] has to be considered and compared with the high specificity of the drugs, which may even be pro-convulsive in epileptic types different from those on which they are proposed $[8,9]$.

Thus, KD's large spectrum of action could be linked to an increase of epileptogenic threshold, rather than blowing out the seizures.

$\mathrm{KD}$, along with starvation, is reported not only to induce ketosis, but also to increase brain norepinephrine (from $100 \pm 15$ to $250 \pm 15$ $\mathrm{pg} / \mathrm{ml}$ in the hippocampus) [10], which has both anticonvulsant and antidepressant effects [11]. Furthermore, an increase of norepinephrine is reported to potentiate the anticonvulsant action of both KD [12] and drugs [13].

Even more importantly, KD is capable of increasing brain NPY level [14], and the same action is reported for valproic acid $[15,16]$ and topiramate [17]. Being NPY an endogenous anticonvulsant, increasing its level must be considered among their anticonvulsant mechanisms $[18,19]$.

Interestingly, KD has been proposed to treat several different clinical conditions: it decreases beta-amyloid plaques in Alzheimer's disease [20], it slows the progression of disease in ALS [21], on rheumatoid arthritis, where an intestinal origin of the pathology has been suggested [22,23], an improvement of $43 \%$ in the rating scales has been reported in Parkinson's [24]. It produces interesting results not only in clinical trials, but also in experimental models of epilepsy $[25,26]$ of ischemia and head trauma [27].

All in all, results have led to put in evidence a neuroprotective role of $\mathrm{KD}$ [28], even without being able to link it to some precise mechanisms. 
We suggest that such a role might be specifically related to the increase of NPY, since it is known to control the brain's self-reparative mechanisms [29]. NPY has been recognized as pivotal in the ILs expression mechanisms [30] involved in inflammation responses, as much as in intestinal inflammation [31] and in immune-modulation [32]. Furthermore it is co-released with norepinephrine and it is fundamental in the gut-brain communication (gut-brain axis) [33]. Such a wide spectrum of action suggests a possible interaction between different districts of the body: therapeutic action on the central nervous system (CNS) could be a reflex induced by an action on the intestinal mucosa.

In the twenties, even without being able to understand the mechanisms, American osteopaths were certain of the role of intestinal inflammation in the pathogenic mechanisms of seizures [34], and at that time, to control seizures, intestinal resections were suggested too [35-37].

Recent studies show that brain inflammation is the pathogenic cause of the seizures [38], it is not simply a predisposing factor, and constitutes a biomarker [39]. Thus, reducing brain inflammation can counteract epileptogenesis [40], and it might be an interesting, innovative tool for seizure control $[41,42]$.

Today, it has been demonstrated that chronic intestinal inflammation migrates to other organs, including the brain [43], and decreases the epileptogenic threshold [44], providing the missing scientific evidence to the osteopaths' theory.

Furthermore, systemic inflammation has been reported to trigger brain inflammation [45], if BBB permeability resulted increased, but it is controlled by intestinal microbiota [46], then our microbe control all inflammation process, in the brain, too.

Thus, lowering the intestinal inflammation can result in a reduction of seizures.

In agreement with this, the anti-epileptic effect of Vagus nerve stimulation (VNS) has been linked with the stimulation of the cholinergic anti-inflammatory pathway [47]. Thus, VNS confirms the role of gut-brain axis and inflammation in seizure controls.

In support to these findings, it has been reported that acetylsalicylic acid is able to control seizures in drug resistant experimental models, apparently by stimulation of self-healing mechanisms [48]. Again, on experimental models, N-palmitoylethanolamine (PEA) has been reported to have an anticonvulsant action [49,50]. It has been demonstrated that PEA exerts a great variety of biological functions related to chronic pain and inflammation, it is proven to have antiinflammatory [51], anti-nociceptive [52] properties and to play a neuroprotective role [53].

Curcumin is another agent reported to be neuroprotective [54] on the basis of results obtained in Parkinson, Alzheimer, epilepsy, stroke, depression and neurodegenerative disorders. Interestingly, it is known to fail to reach the brain for its scarce bio-availability [55]. One more time, evidence demonstrates curcumin to be an intestinal antiinflammatory agent [56].

Curiously, Valproic acid, serendipity discovered to be anticonvulsive, was synthesized from Valeric acid, a component of valerian, used in the past for seizure control. Valeric acid is a short chain fatty acid (SCFA), one of the intestinal cells main nutrients.

SCFAs are obtained by fermentation processes of indigestible fibers (from C2 to C4). The C6 to C12 fatty acids (known as Medium Chain
Triglycerides - MCT), obtained through the same processes, are used in seizures control, alone or together with KD. Both SCAFs and MCTs have a clear role in decreasing the intestinal inflammation [57].

Moreover, VPA has been reported to be a histone deacetylace (HDAC) inhibitor able to significantly improve hemodynamics, intestinal perfusion, and the survival rate after lethal burn shock [58].

These small molecules, inhibitors of HDACs, have been found to trigger both pro- and anti-inflammatory effects, and they are therapeutic promises in inflammatory diseases such as: arthritis, inflammatory bowel diseases, septic shock, ischemia-reperfusion injury, airways inflammation and asthma, diabetes, age-related macular degeneration, cardiovascular diseases, multiple sclerosis and other CNS and neurodegenerative diseases [59].

Again, referring to health of the intestinal mucosa, Alphalactalbumin (ALAC), is a highly effective prebiotic agent of the human intestine, which, through colostrum, activates the newborns' intestine. Several intestinal actions are reported on this whey protein [60-62].

ALACs' efficacy has been reported in several experimental models of epilepsy, in particular it is able to control both types of seizure induced by Pilocarpine [63]. Furthermore, after a period of time of daily ALAC administrations, audiogenic mice continue to be protected by seizures for at least one month from the treatment discontinuation [64]. This evidence suggests that ALAC does not blow out the seizures, but rather decreases the epileptogenic threshold. Surely, ALAC decreases intestinal inflammation, that, once chronic, can migrate to the brain.

Taking in account the role of peripheral inflammation on the pathogenetic mechanisms of seizures, the intestinal actions of antiepileptic drugs has to be considered, since they are orally administrated. Moreover, it is not always possible to know the exact drug's amount able to reach the brain, and if it is comparable with the amount reported to be able to act on neuronal ionic channels by patch clamp experiments. Lacking to know these data, it has been suggested that drug-resistance is due to the expression in the brain of drugresistant proteins that throw the drugs outside the brain [65].

\section{Conclusion}

The recent acquisitions on the role of brain inflammation in the pathogenetic mechanisms of seizures, allow us to re-evaluate the antiepileptic effect of ancient diets.

As a clear consequence to this possibility, we have to consider the intestinal actions of orally administrated drugs, especially taking into account that, for many of them, data on brain intake is unavailable.

Taking in consideration the intestinal action of the drugs allow us to better understand not only their mechanisms of action, but the pathogenetic causes of epilepsy, too. Since, the main action is to decrease intestinal inflammation, the diet becomes pivotal in seizure control.

Potential inflammatory foods could also affect the anti-inflammatory action of drugs, resulting in a decrease of the epileptogenic threshold.

All the aforementioned evidences show that reducing intestinal inflammation increase seizure control by controlling the inflammation process, which triggers seizures. 


\section{References}

1. Geyelin HR (1921) Fasting as a method to treating epilepsy. Med Record 99: 1037-1039.

2. Li HF, Zou Y, Ding G (2013) Therapeutic Success of the Ketogenic Diet as a Treatment Option for Epilepsy: a Meta-analysis. Iran J Pediatr 23: 613-620.

3. Neal EG, Chaffe H, Schwartz RH, Lawson MS, Edwards N, et al. (2008) The ketogenic diet for the treatment of childhood epilepsy: a randomised controlled trial. Lancet Neurol 7: 500-506.

4. Mainardi P, Albano C (2008) Is the antiepileptic effect of the ketogenic diet due to ketones? Med Hypotheses 70: 536-539.

5. Lennox WC, Cobb S (1928) Studies in epilepsy. VIII. The clinical effect of fasting. Arch Neurol Psychiat 20: 771-779

6. Pfeifer HH, Thiele EA (2005) Low-glycemic-index treatment: a liberalized ketogenic diet for treatment of intractable epilepsy. Neurology 65: 1810-1812.

7. Hartman AL (2008) Does the effectiveness of the ketogenic diet in different epilepsies yield insights into its mechanisms? Epilepsia 49 Supp 8: 53-56.

8. Perucca E, Gram L, Avanzini G, Dulac O (1998) Antiepileptic drugs as a cause of worsening seizures. Epilepsia 39: 5-17.

9. Loiseau P (1998) Do antiepileptic drugs exacerbate seizures? Epilepsia 39: $2-4$.

10. Szot P (2004) The Role of Norepinephrine in the Anticonvulsant Mechanism of Action of the Ketogenic Diet in Epilepsy and Ketogenic diet. Stafstrom CE and Rho JM editors,

11. Ahern TH, Javors MA, Eagles DA, Martillotti J, Mitchell HA, et al. (2006) The effects of chronic norepinephrine transporter inactivation on seizure susceptibility in mice. Neuropsychopharmacology 31: 730-738.

12. Martillotti J, Weinshenker D, Liles LC, Eagles DA (2006) A ketogenic diet and knockout of the norepinephrine transporter both reduce seizure severity in mice. Epilepsy Res 68: 207-211.

13. Fischer W, Müller M (1988) Pharmacological modulation of central monoaminergic systems and influence on the anticonvulsant effectiveness of standard antiepileptics in maximal electroshock seizure. Biomed Biochim Acta 47(7): 631-45.

14. Weinshenker D (2004) Eplipesy and ketogenic diet. Stafstrom CE and Rho JM eds. Humana Press.

15. Cansu A, Serdaroglu A, Camurdan O, HÄ \pm rfanoÄŸlu T, Cinaz P (2011) Serum insulin, cortisol, leptin, neuropeptide $\mathrm{Y}$, galanin and ghrelin levels in epileptic children receiving valproate. Horm Res Paediatr 76: 65-71.

16. Brill J, Lee M, Zhao S, Fernald RD, Huguenard JR (2006) Chronic valproic acid treatment triggers increased neuropeptide y expression and signaling in rat nucleus reticularis thalami. J Neurosci 26: 6813-6822.

17. Husum H, Van Kammen D, Termeer E, Bolwig G, Mathé A (2003) Topiramate normalizes hippocampal NPY-LI in flinders sensitive line 'depressed' rats and upregulates NPY, galanin, and CRH-LI in the hypothalamus: implications for mood-stabilizing and weight lossinducing effects. Neuropsychopharmacology 28(7): 1292-9.

18. Colmers WF, El Bahh B (2003) Neuropeptide Y and Epilepsy. Epilepsy Curr 3: 53-58.

19. Vezzani A, Sperk G, Colmers WF (1999) Neuropeptide Y: emerging evidence for a functional role in seizure modulation. Trends Neurosci 22: 25-30.

20. Van der Auwera I, Wera S, Van Leuven F, Henderson ST (2005) A ketogenic diet reduces amyloid beta 40 and 42 in a mouse model of Alzheimer's disease. Nutr Metab (Lond) 2: 28 .

21. Siva N (2006) Can ketogenic diet slow progression of ALS? Lancet Neurol 5: 476.

22. Podas T, Nightingale JM, Oldham R, Roy S, Sheehan NJ, et al. (2007) Is rheumatoid arthritis a disease that starts in the intestine? A pilot study comparing an elemental diet with oral prednisolone. Postgrad Med J 83: 128-131.
23. Sköldstam L, Larsson L, Lindström FD (1979) Effect of fasting and lactovegetarian diet on rheumatoid arthritis. Scand J Rheumatol 8: 249-255.

24. Vanitallie TB, Nonas C, Di Rocco A, Boyar K, Hyams K, et al. (2005) Treatment of Parkinson disease with diet-induced hyperketonemia: a feasibility study. Neurology 64: 728-730.

25. Hori A, Tandon P, Holmes GL, Stafstrom CE (1997) Ketogenic diet: effects on expression of kindled seizures and behavior in adult rats. Epilepsia 38: 750-758.

26. Appleton DB, De Vivo DC (1973) An experimental animal model for the effect of ketogenic diet on epilepsy. Proc Aust Assoc Neurol 10: 75-80.

27. Marie C, Bralet AM, Gueldry S, Bralet J (1990) Fasting prior to transient cerebral ischemia reduces delayed neuronal necrosis. Metab Brain Dis 5: 65-75.

28. Gasior M, Rogawski MA, Hartman AL (2006) Neuroprotective and disease-modifying effects of the ketogenic diet. Behav Pharmacol 17: $431-439$

29. Decressac M, Barker RA (2012) Neuropeptide $Y$ and its role in CNS disease and repair. Exp Neurol 238: 265-272.

30. Rosmaninho-Salgado J, Alvaro AR, Grouzmann E, Duarte EP, Cavadas C (2007) Neuropeptide Y regulates catecholamine release evoked by interleukin-1beta in mouse chromaffin cells. Peptides 28: 310-314.

31. Chandrasekharan B, Nezami BG, Srinivasan S (2013) Emerging neuropeptide targets in inflammation: NPY and VIP. Am J Physiol Gastrointest Liver Physiol 304: G949-957.

32. Holzer P, Reichmann F, Farzi A (2012) Neuropeptide Y, peptide YY and pancreatic polypeptide in the gut-brain axis. Neuropeptides 46: 261-274.

33. Holzer P, Farzi A (2014) Neuropeptides and the microbiota-gut-brain axis. Adv Exp Med Biol 817: 195-219.

34. Conklin HW (1922) Cause and treatment of epilepsy. J Am Osteopathic Assoc. 26: 11-14

35. Read AL (1916) Diagnostic Methods and Pathologic Constants in Idiopathic Epilepsy J.A.M.A: 66: 336 (Jan.29); Constipation and Intestinal Infection in Epileptics, ibid.67:1157 (Oct 14)

36. Read AL (1916) The bacillus epilepticus. Third report. J. Am Med Assoc. LXVI (21): 1607-1611

37. Cuneo G (1922) Biochemical and Biological Researches on the Pathogenesis of Epilepsy, Riv. sper. di freniat., 45, January 31st.

38. Vezzani A, French J, Bartfai T, Baram TZ (2011) The role of inflammation in epilepsy. Nat Rev Neurol 7: 31-40.

39. Vezzani A, Friedman A (2011) Brain inflammation as a biomarker in epilepsy. Biomark Med 5: 607-614.

40. Vezzani A, Friedman A, Dingledine RJ (2013) The role of inflammation in epileptogenesis. Neuropharmacology 69: 16-24.

41. Dedeurwaerdere S, Friedman A, Fabene PF, Mazarati A, Murashima YL, et al. (2012) Finding a better drug for epilepsy: antiinflammatory targets. Epilepsia 53: 1113-1118.

42. D'Ambrosio R, Eastman CL, Fattore C, Perucca E (2013) Novel frontiers in epilepsy treatments: preventing epileptogenesis by targeting inflammation. Expert Rev Neurother 13: 615-625.

43. Riazi K, Galic MA, Pittman QJ (2010) Contributions of peripheral inflammation to seizure susceptibility: cytokines and brain excitability. Epilepsy Res 89: 34-42.

44. Riazi K, Honar H, Homayoun H, Demehri S, Bahadori M, et al. (2004) Intestinal inflammation alters the susceptibility to pentylenetetrazoleinduced seizure in mice. J Gastroenterol Hepatol 19: 270-277.

45. Bañuelos-Cabrera I, Valle-Dorado MG, Aldana BI, Orozco-Suarez SA, Rocha L (2014) Role of Histaminergic System in Blood-Brain Barrier Dysfunction Associated with Neurological Disorders.Arch Med Res. 45(8):677-686.

46. Braniste V, Al-Asmakh M2, Kowal C3, Anuar F2, Abbaspour A2, et al. (2014) The gut microbiota influences blood-brain barrier permeability in mice. Sci Transl Med 6: 263ra158. 
Citation: Mainardi P, Carta P, Striano P, Mainardi M, Montinari M (2015) From the Ancient Diets to the Recent Acquisitions on the Role of Brain Inflammation in Epilepsy, Are there Any Links?. J Neurol Neurophysiol 6: 304. doi:10.4172/2155-9562.1000304

Page 4 of 4

47. Bonaz B, Picq C, Sinniger V, Mayol JF, Clarençon D (2013) Vagus nerve stimulation: from epilepsy to the cholinergic anti-inflammatory pathway. Neurogastroenterol Motil 25: 208-221.

48. Ma L, Cui XL, Wang Y, Li XW, Yang F, et al (2012) Aspirin attenuates spontaneous recurrent seizures and inhibits hippocampal neuronal loss, mossy fiber sprouting and aberrant neurogenesis following pilocarpineinduced status epilepticus in rats. Brain Res. Aug 21; 1469:103-13.

49. Citraro R, Russo E, Scicchitano F, van Rijn CM, Cosco D, et al. (2013) Antiepileptic action of N-palmitoylethanolamine through CB1 and PPAR-Ît receptor activation in a genetic model of absence epilepsy. Neuropharmacology 69: 115-126.

50. Lambert DM, Vandevoorde S, Diependaele G, Govaerts SJ, Robert AR (2001) Anticonvulsant activity of N-palmitoylethanolamide, a putative endocannabinoid, in mice. Epilepsia 42: 321-327.

51. Lo Verme J, Fu J, Astarita G, La Rana G, Russo R et al (2005). The nuclear receptor peroxisome proliferator-activated receptor-alpha mediates the anti-inflammatory actions of palmitoylethanolamide. Molecular Pharmacology 67 (1): 15-19.

52. Calignano A, La Rana G, Piomelli D (2001) Antinociceptive activity of the endogenous fatty acid amide, palmitylethanolamide. Eur J Pharmacol 419: 191-198.

53. Koch M, Kreutz S, Böttger C, Benz A, Maronde E et al (2010). Palmitoylethanolamide Protects Dentate Gyrus Granule Cells via Peroxisome Proliferator-Activated Receptor-Alpha. Neurotoxicity Research 19 (2): 330-340.

54. Kim SJ, Son TG, Park HR, Park M, Kim MS, et al. (2008) Curcumin stimulates proliferation of embryonic neural progenitor cells and neurogenesis in the adult hippocampus. J Biol Chem 283: 14497-14505.

55. Suresh D, Srinivasan K (2010) Tissue distribution \& elimination of capsaicin, piperine \& curcumin following oral intake in rats. Indian J Med Res 131: 682-691.

56. Bereswill S, Muñoz M, Fischer A, Plickert R, Haag LM, et al. (2010) Antiinflammatory effects of resveratrol, curcumin and simvastatin in acute small intestinal inflammation. PLoS One 5: e15099.
57. Kim CH, Park J1, Kim M1 (2014) Gut microbiota-derived short-chain Fatty acids, T cells, and inflammation. Immune Netw 14: 277-288.

58. Hu S, Hou JY, Wang HB, Yang M, Sheng ZY (2012) The effect of valproic acid in alleviating early death in burn shock. Burns 38: 83-89.

59. Halili MA, Andrews MR, Sweet MJ, Fairlie DP (2009) Histone deacetylase inhibitors in inflammatory disease. Curr Top Med Chem 9: 309-319.

60. Yamaguchi M, Takai S, Hosono A, Seki T (2014) Bovine milk-derived Îtlactalbumin inhibits colon inflammation and carcinogenesis in azoxymethane and dextran sodium sulfate-treated mice. Biosci Biotechnol Biochem 78: 672-679.

61. Chatterton DE, Nguyen DN, Bering SB, Sangild PT (2013) Antiinflammatory mechanisms of bioactive milk proteins in the intestine of newborns. Int J Biochem Cell Biol 45: 1730-1747.

62. Yamaguchi M, Yoshida K, Uchida M (2009) Novel functions of bovine milk-derived alpha-lactalbumin: anti-nociceptive and anti-inflammatory activity caused by inhibiting cyclooxygenase- 2 and phospholipase A2. Biol Pharm Bull 32: 366-371.

63. Citraro R, Scicchitano F, De Fazio S, Raggio R, Mainardi P, et al. (2011) Preclinical activity profile of $\hat{I} \pm$-lactoalbumin, a whey protein rich in tryptophan, in rodent models of seizures and epilepsy. Epilepsy Res 95: 60-69.

64. Russo E, Scicchitano F, Citraro R, Aiello R, Camastra C, et al. (2012) Protective activity of $\hat{\mathrm{I}} \pm$-lactoalbumin (ALAC), a whey protein rich in tryptophan, in rodent models of epileptogenesis. Neuroscience 226: 282-288.

65. Sisodiya SM, Lin WR, Harding BN, Squier MV, Thom M (2002) Drug resistance in epilepsy: expression of drug resistance proteins in common causes of refractory epilepsy. Brain 125: 22-31. 